\title{
FEMINISMO NA INTERNET: O CASO DO COLETIVO MARCHA DAS VADIAS E SUA PÁGINA NO FACEBOOK
}

Laís Modelli Rodrigues, Caroline Kraus Luvizotto

Universidade Estadual Paulista "Júlio de Mesquita Filho" - UNESP. Programa de Pós-Graduação em Comunicação. Email: I.modelli@ig.com.br

\section{RESUMO}

Este artigo pretende analisar como os movimentos feministas brasileiros utilizam as redes sociais online para ampliar seu espaço de atuação e mobilização na sociedade, por meio da compreensão de como se dá a atividade do coletivo Marcha das Vadias do Rio de Janeiro na sua página do Facebook e como que esse grupo se mobiliza no ambiente online para organizar a sua Marcha anual, aqui, especificamente, a 4a Marcha das Vadias do Rio de Janeiro. Por meio da pesquisa exploratória, descritiva e analítica de cunho qualitativo e da metodologia de análise de redes sociais na Internet, conclui-se que a rede gerada pelo tema "4a Marcha das Vadias do Rio de Janeiro" foi central e dinâmica entre um público de claras posições feministas, porém fraca e pouco abrangente para dialogar com a sociedade em geral.

Palavras-chave: Internet, redes sociais online, movimentos sociais, feminismo, Marcha das Vadias.

\section{FEMINISM ON THE INTERNET: THE CASE OF THE COLLECTIVE MARCHA DAS VADIAS AND THEIR PAGE ON FACEBOOK}

\begin{abstract}
This article analyzes how the Brazilian feminist movements utilize online social networks to expand their sphere of action and mobilization in society through understanding how is the activity of the collective Marcha das Vadias of Rio de Janeiro on your Facebook page and as this group is mobilized in the online environment to organize its annual march, here, specifically the 4th Marcha das Vadias of Rio de Janeiro. Through exploratory, descriptive and analytical qualitative research methodology and analysis of social networks on the Internet, it is concluded that the network generated by the topic "4th Marcha das Vadias of Rio de Janeiro" was central dynamic between a public clear feminist, but weak and little to comprehensive dialogue with society in general positions.
\end{abstract}

Keywords: Internet, online social networks, social movements, feminism, March of bitches. 


\section{INTRODUÇÃO}

As ferramentas online têm, de diversos modos e níveis, reconfigurado a maneira como as pessoas e instituições se relacionam entre si, com a rede que esses relacionamentos geram e com a sociedade em geral. $\mathrm{O}$ mesmo acontece com os movimentos sociais quando migram para a internet.

Entre os movimentos sociais que se utilizam das possibilidades que a comunicação mediada pela internet oferece destaca-se o movimento feminista, tanto no Brasil como no mundo. Um exemplo recente destacado por Castells (2013) é a participação massiva e representativa de mulheres nas manifestações dos países que promoveram a Primavera Árabe. A violência com que essas manifestantes foram tratadas pelo Governo e pela Polícia não passou despercebida pelo resto do mundo graças à ação de blogueiras e vlogueiras que transmitiam ao vivo via internet os espancamentos, estupros e mortes dessas manifestantes durante as manifestações. Retratou Castells a respeito da revolução no Egito:

Em 19 de dezembro de 2011, durante outro ataque à praça [Tahrir], uma jovem foi espancada, despida e deixada inconsciente, usando apenas o sutiã. Mulheres que tentaram ajudá-la foram atacadas pela polícia. $O$ vídeo mostrando esse bárbaro ato de violência sexista foi disseminado por todo o mundo, provocando a indignação universal, particularmente entre mulheres. Ficou conhecido como o vídeo da "garota de sutiã azul". (CASTELLS, 2013, p. 62)

Logo, observamos que a popularização da internet contribuiu para fazer circular, de forma massiva, discursos de valorização do feminismo (LIMA, 2013, p.10). Mais que isso, as novas dinâmicas comunicacionais mediadas pela internet, assim como a maior presença de temas feministas no campo do estudo e da pesquisa, têm acarretado em novas formas de representação da mulher pela própria mídia. É nesse contexto que movimentos sociais migram para a internet ou até são criados na própria internet, como a Marcha das Vadias, que nasceu de um evento criado no Facebook e só depois alcançou o off-line e a mobilização nas ruas.

Para Castells (2012), o movimento ou demanda social na internet torna-se funcional somente a partir do momento que o âmbito online da questão dialogar com o off-line. Não basta motivar seguidores e opiniões nas redes sociais e blogs, é preciso também levá-los a intervir no espaço urbano, principalmente nos meios simbólicos das cidades, como avenidas, praças e demais espaços públicos.

A partir da metodologia de análise das redes sociais e da pesquisa exploratória, descritiva e analítica de cunho qualitativo, esta pesquisa analisou como os movimentos feministas brasileiros utilizam as redes sociais online para ampliar seu espaço de atuação e mobilização na sociedade. 
Buscou-se a compreensão da atividade do coletivo Marcha das Vadias do Rio de Janeiro na sua página do Facebook, verificando a sua mobilização online para organizar a sua Marcha anual, aqui, especificamente, a 4aㅡ Marcha das Vadias do Rio de Janeiro.

O problema que norteou esse estudo concentra-se em compreender como esse coletivo utilizou a plataforma online e de quais estratégias se apropriou (vídeos, fotos, músicas, poemas, criação de eventos etc) para se comunicar com a sociedade civil de modo geral.

Para tanto, foram analisadas as postagens da Marcha das Vadias do Rio de Janeiro no Facebook de uma semana antes do evento, que aconteceu no dia 09 de agosto, a um dia depois do evento. Ou seja, foram coletados posts entre os dias 04 a 10 de agosto de 2014.

\section{Feminismo brasileiras e suas demandas na internet}

O mundo vive uma nova onda feminista em que questões de gênero conseguem pautar a grande mídia nacional e internacional por causa das possibilidades de maior intervenção das mulheres nos espaços públicos e simbólicos (CASTELLS, 2013, p.58). Isso não significa que as mulheres não se manifestavam em tempos passados, mas que, com o auxílio da internet e das ferramentas online, ficou mais fácil, eficaz e até seguro, para essas feministas exporem suas ideias e demandas para a sociedade.

Do mesmo modo, as questões de gênero baseadas na submissão e rebaixamento da mulher sempre existiram na sociedade, apesar de raramente serem retratadas pela grande mídia de forma direta, mas de forma contínua e subjetiva, se configurando em uma espécie de contraataque aos pequenos ganhos femininos que acontecem de tempos em tempos, como a liberação dos anticoncepcionais, o direito de trabalhar fora, de igualdade salarial etc. Esse clima de contraataque às demandas feministas fez com que a sociedade criasse uma rejeição e uma falta de interesse em compreender o significado profundo da palavra "feminismo" (FALUDI, 2001).

Assim, as mulheres que se manifestam com a ajuda de ferramentas online, como blogs, sites e redes sociais, enfrentam um problema a mais que os movimentos que não estão ligados ao feminismo enfrentam: a rejeição ao termo que as denominam, rejeição essa praticada tanto por homens, quanto por mulheres (LIMA, 2013), tanto nas suas redes online como offline. Ao olharmos para os anos 2000, vemos que blogueiras/os e ativistas feministas na internet são impulsionados a fazerem uso da rede não somente para divulgarem as bandeiras de gênero, mas principalmente para explicarem o que vem a ser o feminismo na sociedade contemporânea.

Reside nesse ponto a relevância em se trazer para a academia as questões de gênero representadas do ponto de vista dos movimentos feministas atuais, como a Marcha das Vadias, 
um movimento que toca na ferida do pensamento machista e patriarcal da sociedade por se apropriar de algo que Lagarde (2005) defende ser o maior cativeiro humano das mulheres: o próprio corpo feminino.

No começo do ano de 2014 aconteceu nas redes sociais um exemplo da força que a manifestação feminista pode alcançar no âmbito da internet, com a repercussão da hashtag \#EuNãoMereçoSerEstuprada: um dia depois que o Instituto de Pesquisa Econômica Aplicada IPEA divulgou que $65 \%$ dos brasileiros acreditam que mulher que mostra o corpo merece ser "atacada", uma jornalista feminista usou seu perfil no Facebook para postar uma foto sua, seminua, com a frase da campanha lançada por ela escrita no próprio corpo \#EuNãoMereçoSerEstuprada. A campanha "viralizou" pela rede e se transformou em um protesto virtual de grande escala. No mesmo instante, a foto foi compartilhada mais de mil vezes e milhares de outras mulheres com conta no Facebook, e até homens, amigos ou não da jornalista que iniciou a ação, postaram suas próprias fotos com a hashtag da campanha. Muitos substituíram suas fotos de perfil pela foto da campanha. Cerca de uma semana depois, o IPEA divulgou nota para informar que havia se confundido com os dados e que o resultado divulgado estava errado: o certo era $26 \%$ e não $65 \%$ os que apoiavam os "ataques" a mulheres. Muitos movimentos feministas brasileiros questionaram se o Instituto, que teve que arcar com o erro dos dados da pesquisa demitindo seu diretor e se retratar em mídia nacional, teria tido o mesmo comportamento se não houvesse tamanha repercussão da campanha \#EuNãoMereçoSerEstuprada.

\section{A Marcha das Vadias nas redes sociais}

A importância de se estudar o surgimento dos coletivos Marcha das Vadias é que do ponto de vista da pesquisa em internet, reside no fato do fenômeno ter sido criado e difundido por meio da internet e das suas ferramentas online, começando como um protesto virtual e depois migrando para os meios simbólicos dos espaços urbanos, conforme proposto por Castells (2013): o movimento social Marcha das Vadias tem suas origens em Toronto, no Canadá, em janeiro de 2011, com o nome original de "SlutWalk". O motivo inicial do protesto foi a fala de um policial que, durante uma palestra de prevenção ao estupro na Universidade de Toronto, afirmou que mulheres deveriam evitar se vestirem iguais a "putas" para não serem estupradas. No dia seguinte, foi postado no Facebook um evento público que convocava mulheres canadenses a marcharem em protesto às formas de repressão e violência contra o corpo feminino. 0 movimento se alastrou pela internet e repercutiu para demais países da América e outros além do continente, como Suécia, Nova Zelândia, Inglaterra e Israel, que também se utilizaram das redes 
sociais na internet para demonstrarem apoio às mulheres canadenses e para organizarem suas próprias marchas.

A primeira marcha no Brasil dessas mulheres que seguiam os protestos da SlutWalk aconteceu em junho de 2011, em São Paulo, com o nome traduzido para "Marcha das Vadias". Em 2012, o movimento alcançou outros Estados e se desmembrou em vários coletivos com o mesmo nome. Mesmo desmembrado, todos os coletivos se organizam em torno das mesmas causas globais de gênero: direito de ir e vir da mulher; direito de se relacionar com quem e da forma que elas desejarem; direito de se vestirem da maneira que Ihes convier, sem a ameaça do estupro, sem a responsabilização da vítima e sem sofrer nenhum tipo de humilhação, repressão ou violência ligada à condição de gênero. No dia 26 de maio de cada ano, todos os coletivos promovem a Marcha Nacional das Vadias e marcham por diversas cidades do país. A edição de 2013 reuniu 13 cidades e sete capitais. Depois, ao longo do ano, cada coletivo promove a própria marcha, como o evento estudado por este artigo, o 4a Marcha das Vadias do Rio de Janeiro, promovido no dia 09 de agosto de 2014.

A Marcha das Vadias do Rio de Janeiro está presente na internet, de maneira autônoma, de quatro formas: com vídeos postados no YouTube (ainda que não tenham um canal próprio do coletivo), com o blog marchadasvadiasrio.blogspot.com, no Twitter @vadiasRJ, com cerca de 487 seguidores, e com a página no Facebook Marcha das Vadias Rio de Janeiro, com cerca de 7.990 curtidas. Para este artigo importa a página do Facebook por ser o mais representativo.

\section{METODOLOGIA: ANÁLISE DE REDE SOCIAL NA INTERNET}

O conceito de rede social é anterior ao surgimento da internet. Assim, olhar para grupos da sociedade estruturados em redes não é algo exclusivo da pesquisa em internet. A análise de redes, para Wasserman e Faust (apud FRAGOSO, AMARAL, RECUERO, 2011), começou com os estudos matemáticos, de aplicação de estatísticas e métodos computacionais no começo do século XX e só posteriormente foram apropriados, na roupagem de redes sociais, pela Ciência Social. Logo, ao organizar de maneira estrutural as interações de um grupo como uma rede, é possível compreender como as interações são construídas entre os atores.

Uma vez inserido no âmbito da internet e das suas dinâmicas comunicacionais estabelecese uma rede social online e a exemplo do trabalho feito no Brasil Recuero, Fragoso e Amaral (2011), este artigo se utilizou do conceito de rede social na internet para observar qual foi o alcance das postagens relacionadas ao evento da Marcha das Vadias do Rio de Janeiro. Ou seja, o conceito metodológico foi útil para compreender qual foi a rede gerada em torno do tema da 
Marcha e como as postagens e atividades na internet do coletivo feminista carioca influenciou na criação, inclusão de novos pontos (outras páginas de Facebook, no caso), manutenção e dinamismo dessa rede.

A nível de critérios metodológicos, a página oficial "Marcha das Vadias Rio de Janeiro" foi nossa representação de ator social. Já um link, um comentário, um compartilhamento, um evento criado pela página, "amigos" adicionados pela página, entre outros recursos que essas redes online permitem, são vários exemplos de conexões que foram coletadas por este estudo para medir o alcance, a repercussão e a centralidade do evento da marcha na rede criada pela Marcha das Vadias.

\section{RESULTADOS E DISCUSSÕES}

A análise das postagens divulgando e chamando para a 4ạ Marcha das vadias do Rio de Janeiro começou no dia 04 de agosto e se estendeu até 10 de agosto de 2014 . O evento ocorreu no dia 09. Ao todo, foram postados, entre compartilhamentos e posts próprios e links de outras redes sociais, 51 publicações. Dessas, 49 eram sobre o evento. As postagens não foram bem distribuídas ao longo dias, sendo apenas 2 no dia 7 de agosto e 30 postagens no dia 10 de agosto, por exemplo.

Dos recursos das redes sociais na internet utilizados pela Marcha no Facebook, observouse: Linkam o Facebook com as postagens do blog do coletivo, promovendo um intercâmbio entre as duas plataformas (ex: "Está no ar o MANIFESTO da Marcha das Vadias do Rio - 2014! http://bit.ly/1zLPoFQ"); Linkam o Facebook com links de outros sites e blogs de conteúdo feminista, mesmo que não tenham ligação com a Marcha das Vadias; Toda postagem é estruturada em um texto inicial opinativo voltado a mulheres na rede e seguido com uma foto ou imagem; O uso de alguns recursos estitlísticos de linguagem de internet, como palavras grafadas em caixa alta, expressam sentimentos e opiniões sobre determinados assuntos (ex: “PRESTENÇÃO, PESSOAS!", “ESSA É A POLÍCIA DO RIO DE JANEIRO!”); Em nenhum post nesse período foi postado vídeo.

No caso da divulgação no Facebook do evento da 4ạ Marcha, além dos recursos apontados: fizeram uma contagem regressiva com uma arte informando onde e quando seria o evento e com "Faltam 5 dias", postados dia a dia até o evento acontecer; postaram outras artes feitas por feministas de outros movimentos e demais ativistas que apoiam a Marcha. Essa ação foi incentivada para enviarem artes para a página do Facebook e para levarem a arte do dia da marcha ("Traga sua arte contra o machismo!"); Deram breves explicações, além do manifesto 
postado no blog e linkado no Facebook, do porque iriam marchar no dia 09 (Ex: "Por isso marchamos!!!" seguido de um link com o título: "Concurso da Secretaria da Educação de SP pede comprovação de virgindade"); Criaram um evento no Facebook para reunir as pessoas que participariam da Marcha em um único ambiente e convidaram pela rede mais de 20 mil pessoas.

Das discussões dos resultados apontados, vemos que a interconexão entre diferentes links, promovidos pelo compartilhamento de outras páginas feministas do Facebook e de links de blogs (no caso, outro tipo de rede social na internet), permite que os seguidores conheçam outros endereços de hiperlinks de conteúdo feminista e conteúdo machista, fortalecendo a rede do feminismo como um todo na internet; utilizam a linguagem própria da plataforma, com uso de imagens associadas a um texto inicial pequeno, fazendo com que a navegação pela página (navegação vertical, de cima para baixa e vice-versa) seja fácil e dinâmica, porém não utilizaram vídeos. Ao compartilharem links de outras páginas na rede, como do blog da Marcha, dão a possibilidade dos seguidores de se aprofundarem nos assuntos que preferirem. Ao promoverem a campanha "Traga sua arte contra o machismo!", a página promoveu o principal fator considerado legitimador de movimentos sociais na internet por Castells (2013): dialogar o ambiente online com o offline, convidando os seguidores da rede social a intervir nos espaços simbólicos urbanos; um dia antes da Marcha, no dia 08, instruíram as pessoas que postassem conteúdo do evento adicionassem a hashtag \#mdvrj; No dia da Marcha, dia 09/08, fizeram postagens direto do evento (“Estamos aqui no concentração! Não tá frio! E tá esquentando... Vem!"), mas não cobriram o evento, deixando isso a cargo da grande mídia. Por último, nas postagens convidando o público para a marcha, deixam claro que o evento é aberto a todos que quiserem se manifestar, desde que não esteja ligado a partidos. Assim, vemos que o movimento feminista tem grande conexão com outros movimentos sociais históricos, como o racial e dos trabalhadores, mas não abarca outros setores da sociedade:

Um informe: a Marcha é um espaço aberto para diversas expressões políticas, artísticas e corporais. Performances e atos diversos são bem-vindos, mas não serão responsabilidade da Marcha das Vadias do Rio de Janeiro. A diversidade é uma tônica e é impossível prever tudo o que pode rolar. Venham com suas convicções, paixões e amor no coração, leveza, alegria, muitas cores, brilhos, glitter, faixas, cartazes e canções. Deixe a bandeira do partido ou candidat@em casa e fortaleça as bandeiras vadias. Façamos uma linda Marcha, vamos marchar!! (Facebook da Marcha das Vadias Rio de Janeiro, postagem 4 de agosto) 


\section{CONSIDERAÇÕES FINAIS}

A página da Marcha das Vadias Rio de Janeiro usa termos próprios dos estudos de gênero no Brasil, mas que não costumam ser muito divulgados e, principalmente, explicados para a sociedade. A página usa em quase todos os posts muitos desses termos, como "cisgênero", "transgênero" etc, e apesar de difundi-los na rede, não explicam o que vem a ser esses termos. Dificultam, assim, que pessoas não ligadas a rede, no caso pessoas que não tenham familiaridade com a causa feminista, adentrem à rede.

Outras limitações encontradas na estratégia de divulgação da página: a Marcha não responde os comentários deixados nos posts, quebrando ou deixando de construir novas conexões criadas de forma espontânea na rede pelos seguidores; As postagens feitas direto do evento não se configuraram em uma cobertura em tempo real da Marcha, pois se limitavam em fazer aquilo que já haviam feito a semana toda: chamar as pessoas a marchar. Somente no dia seguinte que foi postado fotos do evento na página.

Observamos que a rede construída pela Marcha das Vadias Rio de Janeiro em torno da 4a Marcha foi grande, com cerca de 5 mil pessoas que informaram no evento do Facebook que compareceriam na manifestação. Essa rede construída no ambiente online, no entanto, não foi capaz de incluir novos personagens, aqueles que não conhecem as causas feministas; essa rede também não foi capaz de incluir as pessoas que incentivaram a marcha, mas que não puderam comparecer no evento. Assim, vemos que o movimento feminista na internet, com base na página Marcha das Vadias Rio de Janeiro durante a semana da 4a Marcha, é eficaz em falar para os seus simpatizantes, porém têm dificuldade de falar com mais pessoas de perfis diferentes, abrangendo a sociedade geral.

\section{Referências}

CASTELLS, Manuel. Redes de indignação e esperança - movimentos sociais na era da internet. Rio de Janeiro: Editora Zahar, 2013.

FALUDI, Susan. Backlash: o contra-ataque na guerra não declarada contra as mulheres. Rio de Janeiro: Rocco, 2001.

FRAGOSO, Suely; RECUERO, Raquel; AMARAL, Adriana. Métodos de pesquisa para internet. Porto Alegre: Sulina, 2011.

LAGARDE, Marcela y de los Ríos. Los cautiverios de las mujeres - madresposas, monjas, putas, presas y locas. Cidade do México: Universidad Nacional Autônoma do México, 2005. 
LIMA, Quézia dos Santos. Blogueiras feministas e o discurso de divulgação do feminismo no ciberespaço. In: Seminário de estudos em análise do discurso, 6, 2013, Rio Grande do Sul. Estudos em Análise do Discurso. Rio Grande do Sul: Instituto de Letras, 2013. Disponível em: <http://www.ufrgs.br/analisedodiscurso/anaisdosead/6SEAD/SIMPOSIOS/BlogueirasFeministasEO Discurso.pdf>. Acesso em: 22 mar. 2014. 